\title{
Nonuniform Oxidation Behavior of Loaded Gasoline Particulate Filters
}

\author{
Melanie Moses-DeBusk ${ }^{1}$ (D) John M.E. Storey ${ }^{1} \cdot$ Mary A. Eibl $^{1} \cdot$ John F. Thomas ${ }^{1} \cdot$ Todd J. Toops $^{1}$. \\ Charles E.A. Finney ${ }^{1} \cdot$ Josh A. Pihl ${ }^{1} \cdot$ Hassina Z. Bilheux ${ }^{2} \cdot$ Jens Gregor $^{3}$
}

Received: 27 August 2019 / Revised: 11 June 2020 / Accepted: 15 July 2020 / Published online: 21 July 2020

(C) The Author(s) 2020

\begin{abstract}
The results of an experimental study on the oxidation behavior of loaded gasoline particulate filters (GPFs) from a gasoline direct injection (GDI) engine are reported. PM was loaded on uncatalyzed cordierite GPF mini-cores by exposure to exhaust from a light-duty GDI engine operating during a rich acceleration condition on four fuels: $100 \%$ gasoline (E0); a 30\% blend of ethanol in gasoline (E30); a $24 \%$ blend of isobutanol in gasoline (iBu24); or a $48 \%$ blend of isobutanol in gasoline (iBu48). The oxidative reactivities of these four types of PM were investigated as a function of temperature. Compared with E0, particulate matter (PM) from the ethanol blend showed a significant shift to lower temperature activity, whereas both isobutanol blends produced PM requiring higher temperatures to achieve complete oxidation. The oxidation kinetics of the E0 and E30 PM were studied in more detail. These cores were used in pulsed-oxidation studies to explore the oxidation kinetics of the PM throughout a stepwise burnout (i.e., regeneration). The results suggest that the reactivity of PM on GPF cores is sensitive to both its environmental history and the type of fuel being used. A unique neutron-imaging study was also performed on E0 and E30-loaded GPF cores to study how the PM layer thicknesses change during a stepwise burnout.
\end{abstract}

Keywords Gasoline particulate filter $\cdot$ Activation energy $\cdot$ Particulate matter $\cdot$ Soot $\cdot$ Neutron imaging

\section{Introduction}

The automotive industry's efforts for improving fuel efficiency to meet new standards and regulations have

This manuscript has been authored by UT-Battelle, LLC under Contract No. DE-AC05-00OR22725 with the US Department of Energy. The US Government retains and the publisher, by accepting the article for publication, acknowledges that the US Government retains a non-exclusive, paid-up, irrevocable, worldwide license to publish or reproduce the published form of this manuscript, or allow others to do so, for US Government purposes. The Department of Energy will provide public access to these results of federally sponsored research in accordance with the DOE Public Access Plan (http://energy.gov/downloads/doe-publicaccess-plan).

Melanie Moses-DeBusk

mosesmj@ornl.gov

1 Energy and Transportation Science Division, Oak Ridge National Laboratory, Oak Ridge, TN, USA

2 Neutron Scattering Division, Oak Ridge National Laboratory, Oak Ridge, TN, USA

3 Department of Electrical Engineering and Computer Science, University of Tennessee, Knoxville, TN, USA resulted in an evolution of the gasoline engine. By 2018, gasoline direct injection (GDI) engines were in $51 \%$ of all new light-duty automobiles sold in the USA, while the European Union (EU) researched this same level in 2017, surpassing light-duty diesel cars for the first time $[1,2]$. It has been consistently shown that the switch from port fuel injection (PFI) to GDI increased both the number and mass of particulate matter (PM) [3-5]. Furthermore, the adoption of lean-GDI operation for improved fuel efficiency could lead to even greater PM emissions [6-8].

Whereas the switch to GDI improves fuel economy [9] compared with PFI, GDI can result in increased air-fuel stratification and fuel-spray impingement on combustion-chamber surfaces, potentially promoting PM formation [10-12]. Similarly, recent studies have reported on the impact of engine operating conditions [13-15] and fuel properties $[16,17]$ on GDI PM.

Simultaneous with the move away from PFI, which produced little to no PM, to GDI was the implementation of more stringent vehicle emission regulations for PM globally. The US Environmental Protection Agency (EPA) began phasing in Tier 3 PM emission standards with MY2017 [18]. The Tier 3 standard drops the allowable PM mass emission rate $70 \%$ 
from 10 to $3 \mathrm{mg} / \mathrm{mile}$ over the urban driving schedule of the federal test procedure (FTP), with $100 \%$ fleet phase-in to be completed by MY2022. The California Air Resources Board currently has a similar $3 \mathrm{mg} / \mathrm{mile}$ PM emission regulation as part of its low emission vehicle (LEV) III standard that also began phase-in with MY2017, but also calls for a 1-mg/mile standard with a proposed phase-in to start with MY2025 [19]. The EU implemented a particle number $(>23 \mathrm{~nm})$ regulation of $6 \times 10^{11} \# / \mathrm{km}\left(9.7 \times 10^{11} \# /\right.$ mile $)$ for GDI vehicles under Euro 6 in addition to the PM mass regulation of $4.5 \mathrm{mg} / \mathrm{km}$ $(7.2 \mathrm{mg} / \mathrm{mile})[2,20]$. China introduced the same particle number and PM mass regulation as the Euro 6 in their CN5 regulations, but required a drop to $3 \mathrm{mg} / \mathrm{km}(4.8 \mathrm{mg} / \mathrm{mile})$ in their C6b targets with 2023 implementation [20]. As these mass-based PM emission regulations continue to become more stringent in the USA, and with the introduction of particle number regulations in the EU and China, there is a critical need for more research into the properties of GDI PM.

While diesel studies often refer to PM as soot due to the high fraction of elemental carbon type particulate, PM can also include organic carbon and inorganic ash particles. The compositional distribution of these types of particulate in PM can be influenced by changes in combustion strategies and fuel properties [21, 22]. For accuracy, this paper will use the more inclusive PM term, unless discussing a specific component of the PM emissions.

A wall-flow GPF, similar to a diesel particulate filter (DPF), is already a part of aftertreatment strategies to control particle number and PM emissions in the EU and other countries and may become necessary in the USA to meet future regulations. The widespread implementation of DPFs in diesel vehicles has led to a better understanding of the filtration mechanism. Partially loaded DPFs have greater PM removal efficiency than clean DPFs due to layers of previously trapped PM that act as metastable filtration layers on the DPF for subsequently generated particulate. However, in GPFs, the higher temperatures of gasoline exhaust with fuel cut events result in passive regeneration during normal vehicle operation, preventing a PM layer buildup [23]. It has also been shown $[24,25]$ that varying the location and loading of a washcoat on a catalyzed DPF can alter the porous structure of the particulate filter, further improving filtration efficiency. Recent studies on catalyzed GPFs have investigated how GPF ash accumulation could promote a similar type of increase in filtration efficiency [26, 27]. Ash accumulation has been reported to provide significant improvement to the filtration efficiency of a GPF over the vehicle lifetime [28]. Non-ash PM can also be expected to accumulate in vehicles which are not routinely driven at the higher speeds required for passive regeneration [29]. When PM accumulation does occur in GPFs, it can be located both on and in the porous filter walls. The potential for short-term buildup of PM on the GPF and/or the PM's interaction with catalytic active sites, in cases where the emission control catalyst and particulate filter are combined, have created an increased interest in the oxidative reactivity of PM, which would also be relevant when consumer driving behavior requires active regeneration. An understanding of the oxidative reactivity is critical to developing both system models of the powertrain-GPF interactions and operational controls for managing PM accumulation in the GPF [30].

Reactivity measurements are commonly taken from thermal gravimetric analysis (TGA) of PM samples collected on quartz fiber filters or loose particulate knocked off wall-flow particulate filters after filter loading on an engine or a vehicle. The activation energies are then calculated using the Arrhenius equation on small segment extractions from the TGA results and therefore are non-isothermal. TGA, within a given study, can highlight the effects that a set of conditions has on the activation energy of PM samples; however, variances between experimental procedures used in different reported studies can make direct quantitative comparisons less accurate. The impact of different TGA experimental procedures, such as sample mass, temperature window integration, and ramp rate, has been noted in the literature, and activation energy calculations for PM samples from the same study vary widely, ranging from 67 to $256 \mathrm{~kJ} / \mathrm{mol}$ [12, 30-32]. Wang et al., in a non-isothermal kinetic study, showed that ramp rate and initial PM mass used in the study impacted the calculated activation energy for the same PM [31]. Luo et al. reported the PM activation energy increased relative to the engine speed-load condition at which it was generated for series of fuels and that increasing ethanol blending reduced the activation energy at all engine conditions tested [12]. Bogara et al. reported results from an isothermal kinetic study using separate PM samples to measure oxidation rate at different temperatures, ranging from 400 to $750{ }^{\circ} \mathrm{C}$, which gave an activation energy of $132 \mathrm{~kJ} / \mathrm{mol}$ for E0 PM. In addition, they found a range of activations energies $(\sim 140$ $160 \mathrm{~kJ} / \mathrm{mol}$ ) for the same PM in non-isothermal studies at different ramp rates and sample masses, leading them to suggest that due to the impacts of ramp rate and initial mass of the sample on activation energy, these values should be used to understand trends but absolute values should be taken with caution [30]. Furthermore, since most TGA studies are on loose PM or PM on a microfiber filter, in contrast to an actual GPF which has a wall-flow, monolithic structure, the typical TGA approach must assume a uniform PM sample with a single activation energy regardless of whether the study uses a nonisothermal ramping method on a single sample or isothermal oxidations on multiple samples.

To better understand the oxidative reactivity of GDI PM in a GPF-based aftertreatment control system, the PM in the present study was loaded on small uncatalyzed GPFs during engine-dynamometer operation. To accumulate enough PM to study its oxidation kinetics, it was necessary to achieve a complete PM layer in the GPF. Although this is not fully representative of what is expected in the field, it is the only 
reasonable way to accumulate enough PM to study its oxidation kinetics in the mini-GPF cores required for the flow reactor setup. Additionally, the impact of oxygenated fuel blends on oxidative reactivity was investigated by comparing GPFs loaded with PM generated from gasoline with and without ethanol (E0 and E30). The GPF-loaded PM layers were then studied throughout exposure to successive oxidative burnouts. Studying PM reactivity sequentially on a GPF in a simulated exhaust gas flow reactor allowed the exposed surface area and PM layer morphology to factor into the activity measurements unlike typical TGA studies. Another benefit of having a PM layer in the GPFs is that it enables a better comparison for how the GDI-generated PM behaves contrasted to DPF PM layers reported in the literature [33, 34]. Thickness measurements made during successive burnouts with neutron imaging revealed distinct differences between the two.

Oxygenated fuels have been shown to improve efficiency as well as provide pathways to increase the use of renewable fuels. The US Department of Energy has an ongoing vehicle technology initiative, Co-Optima, on fuels and engine optimization which has actively investigated both bio-derived fuel production pathways and their impact on engine operation. Only two of the most promising blendstocks found in this program for light-duty vehicles, ethanol and isobutanol, are currently allowed in market fuels [35]. The USA currently promotes the use ethanol fuel blending of $10 \%$ (E10) for onroad vehicles and allows $15 \%$ ethanol (E15), while isobutanol $(\mathrm{iBu})$ is approved for blending up to $16 \%$ in market fuels. Increased alcohol blending levels are of interest due to its potential to enhance emission reduction and improve engine efficiency at lower blending levels, with E30 being one of the most promising candidates [36, 37]. To achieve the same fuel oxygen content as E30, a $48 \%$ iBu blend was also used in this study. The impact of isobutanol blended fuels on PM emission flux and particle size has been discussed in the literature [14, 38]. Prior work has shown that blending of ethanol with gasoline results in an increased reactivity of GDI PM [12, 14, 31]. The purpose of this study was to measure the fundamental oxidation kinetics for PM loaded on wall-flow GPFs in the exhaust of a GDI engine running on several different fuels containing varying levels of ethanol and isobutanol.

\section{Experimental}

\subsection{Engine, Fuels, and GPF Core Loading}

The GPF samples were collected according to a previously described process [16]. The process is briefly described here. Particulate matter was loaded on uncatalyzed, cordierite miniGPF cores $(2.5 \mathrm{~cm}$ outer diameter $\times 7.6 \mathrm{~cm}$ long; NGK $12 \mathrm{mil} /$ $300 \mathrm{cpsi}$ ) by placing them four at a time in a special holder that directed the exhaust from a 2.0-L GM GDI engine, downstream of the catalyst, to flow in parallel through all four filters. This engine was specifically developed for high-efficiency operation with ethanol fuel blends. During GPF loading, the engine was operated under acceleration type conditions of $2600 \mathrm{rpm}$ and 8 bar brake mean effective pressure at air-tofuel ratios slightly higher than the engine's minimal lambda $(\lambda)$ of 0.89 . At stoichiometric engine operation, there is exactly enough oxygen to combust all of the fuel hydrocarbons $(\lambda=$ 1 ), while at $\lambda<1$, as was used in this study, there is an excess of fuel. Prior to PM loading, the cores were ramped in air to $800{ }^{\circ} \mathrm{C}$ in a tube furnace to bake off any unknown impurities in the filter. Cores were loaded (ca. $4 \mathrm{~g}$ of PM per liter of filter) with PM from one of the four different volumetric fuel blends: an 87 anti-knock index (AKI) gasoline (E0), a 30\% ethanol blend with the 87 AKI gasoline (E30), a $48 \%$ isobutanol blend with the 87 AKI gasoline (iBu48), or a $24 \%$ isobutanol blend with the 87 AKI gasoline (iBu24). PM collection quantities were determined by the change in filter weight before and after PM loading. Mass measurements were collected after drying the cores in $\mathrm{a} \sim 120^{\circ} \mathrm{C}$ laboratory oven for about $2 \mathrm{~h}$ and weighed directly after removal from the oven.

\subsection{Flow Reactor Experiments}

\subsubsection{Oxidation Study: Temperature Programed Oxidation}

All oxidation studies were carried out on an automated flow reactor similar to the one described by Pihl et al. [39]. The GPF was placed at the end of a Mini-Mite $\AA$ tube furnace inside a quartz tube, and the feed gases were supplied upstream of the furnace and metered in using a manifold of mass flow controllers (MFCs). The water was supplied by a highpressure liquid chromatography pump which introduced the water directly into a heated flow of nitrogen. Fast-switching valves downstream of the MFCs but upstream of the furnace were used to control pulsed flows when needed. An MKS MultiGas 2030HS Fourier transform infrared (FTIR) spectrometer downstream of the GPF was used to monitor gas composition. The $\mathrm{CO}_{2}$ was quantified with a custom low concentration calibration developed in collaboration with MKS; all other gases were quantified using standard calibrations provided by MKS. A high-pressure liquid nitrogen dewar and an ultra-high purity compressed oxygen cylinder were used to feed the MFCs.

The temperature dependence for oxidation of each type of PM produced was studied by temperature programed oxidation (TPO). The oxidative reactivities of the PM produced from the different fuel blends (E0, E30, iBu24, iBu48) were measured with the PM still loaded on the GPF mini-cores. The TPO experiments were run at a gas hourly space velocity (GHSV) of $20,000 \mathrm{~h}^{-1}$ in the presence of $1 \% \mathrm{O}_{2}$ and $10 \% \mathrm{H}_{2} \mathrm{O}$ with a $\mathrm{N}_{2}$ balance at a $10{ }^{\circ} \mathrm{C} / \mathrm{min}$ temperature ramp from 150 to $650{ }^{\circ} \mathrm{C}$ 
(E0 and E30) or 150 to $700{ }^{\circ} \mathrm{C}$ (iBu24 and iBu48). For calculation purposes, all PM mass on the GPFs were assumed to be carbon, and its removal was calculated from a mass balance based on the moles of $\mathrm{CO}$ and $\mathrm{CO}_{2}$ measured by the FTIR downstream of the flow reactor furnace.

\subsubsection{Oxidation Study: Kinetics}

Kinetic studies were only performed on PM from the E0 and E30-loaded GPF cores. The same automated flow reactor described in Section 2.1 was also used for these experiments. The kinetic studies were conducted in a stepwise fashion, summarized in Table 1, on a single core sample and encompassed four different types of oxidation treatments run in the following order:

(1) Burnout oxidation: Step 1, to remove the required moles of carbon to advance the PM layer to the next $C / C_{0}$ level to be studied $\left(C_{0}\right.$ is the initial moles of PM loaded on the filter, and $C$ is the cumulative moles of PM removed by oxidation);

(2) Pulsed oxidation-temperature sweep: Steps 2-6, used for activation energy calculation;

(3) Pulsed oxidation- $\mathrm{O}_{2}$ sweep: Steps 6-10, to probe the $\mathrm{O}_{2}$ dependence of the oxidation rate;

(4) Temperature programed desorption (TPD) oxidation, Steps 11-12, for active surface area calculations.

The four-part kinetic study was repeated, unless otherwise noted, at five different levels of GPF burnout, nominally, $\mathrm{C} /$

Table 1 Experimental steps involved in the 4 types of oxidation treatment used to study each burnout level of a GPF

\begin{tabular}{llllll}
\hline Step & $T\left({ }^{\circ} \mathrm{C}\right)$ & $\mathrm{O}_{2}(\%)$ & $\mathrm{H}_{2} \mathrm{O}(\%)$ & $\mathrm{GHSV}\left(\mathrm{h}^{-1}\right)$ & Pulses $^{\mathrm{a}}$ \\
\hline 1 & $120-440$ & 20 & 10 & 10,000 & $b$ \\
2 & 400 & 20 & 10 & 10,000 & 5 \\
3 & 410 & 20 & 10 & 10,000 & 5 \\
4 & 420 & 20 & 10 & 10,000 & 5 \\
5 & 430 & 20 & 10 & 10,000 & 5 \\
6 & 440 & 20 & 10 & 10,000 & 5 \\
7 & 440 & 17 & 10 & 10,000 & 5 \\
8 & 440 & 12 & 10 & 10,000 & 5 \\
9 & 440 & 8 & 10 & 10,000 & 5 \\
10 & 440 & 5 & 10 & 10,000 & 5 \\
11 & 200 & 20 & 0 & 4000 & $c$ \\
12 & $200-650$ & 0 & 0 & 4000 & \\
\hline
\end{tabular}

${ }^{\mathrm{a}} \mathrm{O}_{2}$ pulses were $30 \mathrm{~s}$ long with $150 \mathrm{~s}$ recovery time before the next pulse

${ }^{\mathrm{b}} \mathrm{O}_{2}$ turned on once a stable $\mathrm{H}_{2} \mathrm{O}$ concentration was achieved, ramp continued until desired moles of carbon were removed

${ }^{\mathrm{c}} \mathrm{O}_{2}$ flow at $200^{\circ} \mathrm{C}$ for $2 \mathrm{~h}$
$C_{0}=0,0.2,0.4,0.6$, and 0.8 PM burnout, where $C / C_{0}=0$ refers to the first tests on the fully loaded filter. The term burnout will be used to refer to the total cumulative fraction of the initial PM that has been removed by any previous oxidation steps or treatments $\left(C / C_{0}\right)$. The conditions for these studies are summarized in Table 1 and described in the preceding sections. Multiple GPF cores loaded with PM from either E0 or E30 were used for repeating the kinetic studies.

Burnout Oxidation Each GPF was prepared for the next burnout level to be studied by oxidizing the remaining moles of $\mathrm{PM}$ on the GPF to reach the next $C / C_{0}$ level. This step (step 1 of Table 1) is referred to as the burnout oxidation treatment (Fig. 1). The $\mathrm{CO}$ and $\mathrm{CO}_{2}$ evolved from the PM oxidation were integrated in real time by the simulated exhaust flow reactor control software, and feedback control was used to shut off the $\mathrm{O}_{2}$ flow when the total moles of carbon burned reached the target threshold.

Pulsed Oxidation-Temperature Sweep The pulsed oxidationtemperature sweep studies, steps 2-6 of Table 1, were carried out at each burnout level. The pulse conditions and temperatures were chosen to achieve reproducible oxidation rates without consuming significant quantities $(<10 \%)$ of the PM. The conditions were chosen based on the TPO results of E30 to reduce the potential for excessive burnout at a single temperature but were also used for $\mathrm{E} 0$ so that a direct comparison could be made.

Similar to a pulsed-oxidation study done on DPF minicores [39], the reactivity was averaged over the second half (last $15 \mathrm{~s}$ ) of the last 3 pulses at each temperature in an attempt to capture stable activity. Reactivity was measured by this method at all 5 temperatures for each target burnout levels for 2-3 loaded GPFs and averaged for each temperature- $C$ / $C_{0}$ condition studied. The PM activation energies at each burnout level were calculated from Arrhenius plots of the average isothermal reactivity measurements.

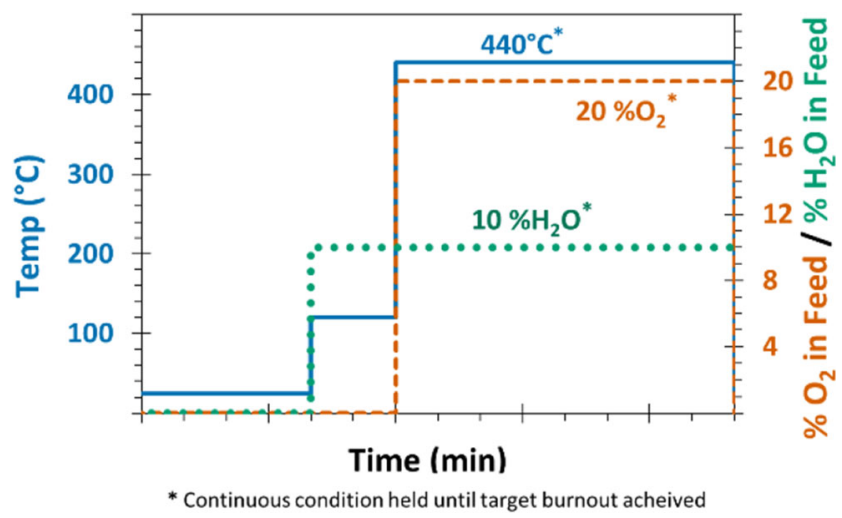

Fig. 1 Experimental conditions used for the burnout oxidation treatment. "-" target temperature profile, "—_ $\% \mathrm{O}_{2}$, and "॰" $\% \mathrm{H}_{2} \mathrm{O}$ in the feed gas 
Pulsed Oxidation-02 Sweep A second set of pulsed oxidations, pulsed oxidation- $\mathrm{O}_{2}$ sweep, was performed at $440{ }^{\circ} \mathrm{C}$ according to conditions listed for steps 6-10 of Table 1 . The resulting reaction rates were used to determine the $\mathrm{O}_{2}$ dependence of the PM oxidation kinetics for each burnout level.

Temperature Programed Desorption Oxidation Following the pulsed oxidation- $\mathrm{O}_{2}$ sweep, a TPD oxidation experiment was run to estimate the active specific surface area [39] of the PM. The TPD oxidation protocol is shown in Fig. 2 and represented in steps 11-12 of Table 1. Integration of the $\mathrm{CO}$ and $\mathrm{CO}_{2}$ evolved during the oxygen-free portion of the TPD experiment was used to calculate the PM oxygen uptake that occurred during the $200{ }^{\circ} \mathrm{C} \mathrm{O}_{2}$ exposure. The $\mathrm{PM} \mathrm{O}_{2}$ uptake could then be used to calculate the active specific surface area per mole of PM remaining $\left(S_{\mathrm{m}} ; \mathrm{m}^{2} \mathrm{~mol}^{-1}\right)$ at each $C / C_{0}$ level; calculations assumed a cross-sectional area of $6800 \mathrm{~m}^{2} \mathrm{~mol}^{-1}$ [39] for the adsorbed atomic oxygen.

\subsection{Neutron Imaging of GPFs}

In a previous study on successive regeneration of DPFs [33], neutron imaging was demonstrated to be a powerful, nondestructive technique capable of detecting thin layers of PM and ash on the filter walls with high spatial resolution throughout the volume of the filter. In the present study, a similar neutronimaging procedure was conducted on E0 and E30 GPF cores loaded with PM like those used for the oxidation studies. Each $\mathrm{GPF}$ was first imaged with $\sim 4 \mathrm{~g}_{\mathrm{PM}} / \mathrm{L}_{\mathrm{GPF}}$ loading $\left(C / C_{0}=0\right)$. The cores were then individually placed in the simulated exhaust reactor, and a partial burnout of the PM was performed to take the core to the next PM burnout level. Both the E0 and E30 GPF cores were imaged at 6 nominal burnout levels $(C)$ $C_{0}=0,0.2,0.4,0.6,0.8$, and 1.0). The burnout procedure was the same as that used in the kinetic study and can be found as step 1 in Table 1.

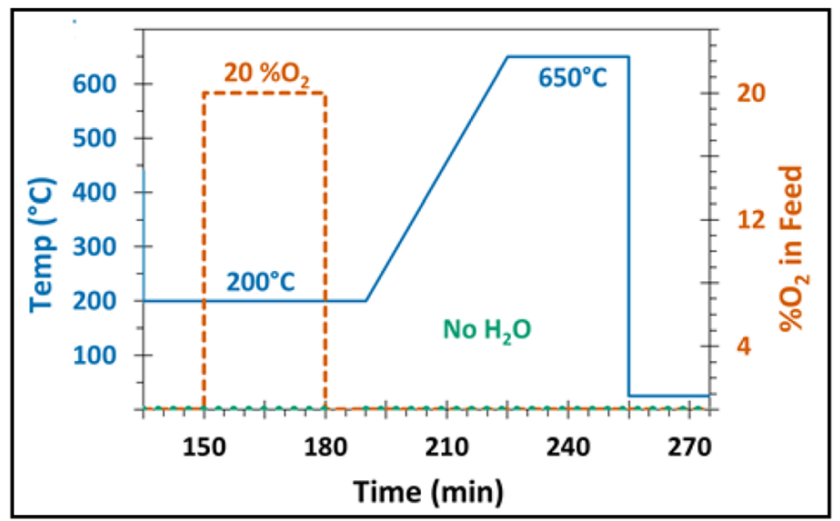

Fig. 2 Experimental conditions used for TPD oxidation treatment. "-" temperature profile, "—_ $\% \mathrm{O} 2$, and "•." $\% \mathrm{H} 2 \mathrm{O}$ in the feed gas

\subsubsection{Neutron Tomography}

The High Flux Isotope Reactor at Oak Ridge National Laboratory generates a neutron flux of $2.5 \times 10^{15} \mathrm{n} \mathrm{cm}^{-2} \mathrm{~s}^{-1}$ at $85 \mathrm{MW}$ thermal power, making it one of the most powerful neutron sources for scientific research in the world. Some of these neutrons are diverted into over a dozen thermal or cold beamlines, and the Cold Guide 1D beamline (CG-1D) is devoted to imaging. The flux at the CG-1D aperture is typically $\sim 10^{6}-10^{7} \mathrm{n} \mathrm{cm}^{-2} \mathrm{~s}^{-1}$, and the neutron beam diverges at $2.7^{\circ}$ traveling through a 450-cm long He-filled flight tube up to $565 \mathrm{~cm}$ to the imaging detection plane; by varying sample locations and/or aperture sizes, L/D (post-aperture flight path to aperture diameter, for a pinhole geometry) ratios $\sim 400-800$ may be obtained, resulting in different levels of resolution. Imaging is achieved by measuring the relative interaction, via absorption and scattering, of materials and neutrons between the aperture and the detector [34, 40].

At the detection plane is a 50 or $100-\mu \mathrm{m}$ thick ${ }^{6} \mathrm{LiF} / \mathrm{ZnS}$ scintillator plate, orthogonal to the neutron beam, which emits photons from neutron collisions. These photons are measured with a 16-bit $2048 \times 2048$ pixel DW936 IkonL ANDOR ${ }^{\mathrm{TM}}$ CCD camera with a $7.4 \times 7.4 \mathrm{~cm}$ field of view on the scintillator, for a pixel size of $\approx 0.0040 \mathrm{~cm} \mathrm{px}^{-1}$. The resolution of this system is typically $0.0070-0.0200 \mathrm{~cm}$ depending on a variety of factors. The camera can transmit images at 1 frame/s, but typically $15-60 \mathrm{~s}$ of integrated exposure is required for sufficient contrast. Sample images are normalized between the open-beam image, which contains inhomogeneities in the beam caused by the neutron path guide structures, and a dark-field image, which represents internal camera current with no exciting photons.

The tomographic imaging procedure was conducted as in our previous study [33] on progressive regeneration in diesel particulate filters. Both GPFs were placed side by side in a special holder placed upon a rotational stage with $0.05^{\circ}$ rotational angle precision. The GPF flow channels were oriented vertically, or perpendicular to the stage table surface. The tomographic radiographs were obtained by rotating the stage through a $183^{\circ}$ range with $0.1^{\circ}$ steps, and at every step, a radiograph was obtained, for a total of 1831 radiographs. The radiographs were normalized, as described above, and filtered using a median filter to remove small, localized spots in the images where incident gamma radiation saturated the detector before the tomographic reconstruction.

\subsubsection{Tomographic Reconstruction}

An iterative reconstruction algorithm was employed, a method which generally yields greater image contrast than an analytic algorithm such as filtered back projection. Image reconstruction was modeled as a regularized weighted least squares problem, which was solved using a SIRT-like (Simultaneous 
Iterative Reconstruction Technique) preconditioned gradient descent (PGD) algorithm, more specific details of which have been previously reported [41, 42].

Some computational techniques were implemented for computational and data memory efficiency. First, ordered subsets were used to accelerate the PGD algorithm, a multithreaded approach that took advantage of the multi-core architecture of modern-day computers. The number of subsets was set to one-fourth of the number of projections during the first several iterations and was then gradually tapered off to one for the last few iterations. This approach accelerated the computation as much as possible early on and prevented ending up in a limit cycle toward the end. Second, to reduce the data memory requirements, the voxel size in the axial direction (along the GPF channel) was set to $\approx 0.03 \mathrm{~cm}$, retaining the $0.004 \mathrm{~cm}$ voxel width across the channels to measure PM thickness.

\subsubsection{Data Analysis}

The data analysis procedure was conducted as in our previous study on progressive regeneration in diesel particulate filters [33]. Because the contrast between PM and the filter walls was too low to discriminate reliably and the PM layer was usually thinner than the detector resolution, the methodology for determining PM thickness outside of the filter walls relied on the differences in flow area between the outlet and the inlet channels. These differences are apparent in Fig. 3, which shows neutron tomographic sections, or slices, at the axial midpoint for the fully loaded and fully regenerated E0 GPF. In the fully loaded slice, there is a visibly apparent bias, with alternating smaller-area channels (the inlet channels with a PM layer) and larger-area channels (the outlet channels without PM); this pattern is not apparent in the fully regenerated slice. The following methodology was used to quantify these differences and estimate PM layer thickness: A set intensity threshold was used to differentiate between the open channel and the wall, and the channel pixel area was the set of contiguous pixels with sub-threshold intensities; both inlet and outlet channel areas were calculated in this manner, and the areas were computed for each channel of interest for each tomographic slice along the GPF axis. A schematic of the area computation process for a given inlet channel is shown in Fig. 4, in which the pixel area $A_{\mathrm{i}}$ for the inlet channel and pixel areas $A_{\mathrm{o}, \mathrm{n}}$ for $n$ (up to 4) neighboring outlet channels are calculated using image analysis; the $A_{\mathrm{o}, \mathrm{n}}$ was averaged to obtain a single $A_{\mathrm{o}}$. On average, the PM layer thickness, $e$, will be:

$e=\frac{b-a}{2}=\frac{\sqrt{A_{\mathrm{o}}}-\sqrt{A_{\mathrm{i}}}}{2}$.

As a result, the PM layer thickness for a given inlet channel was calculated as a function of axial distance, for all 6 regeneration stages. An ensemble of axial thickness functions from several dozen inlet channels was computed at each regeneration step, and the axially resolved mean thickness profile was computed as a final result.

The measured dispersion within the ensemble of PM layer thickness profiles was pronounced, but the mean profiles for each regeneration step followed a clear trend as more PM was removed. The $C / C_{0}=1.0$ case, which removed all of the PM, was used to determine if there was an intrinsic difference in dimensions between the inlet and outlet channels. Using the method of areas as described above, the measured PM layer thickness for $C / C_{0}=1.0$ was $\pm 0.0010 \mathrm{~cm}$, placing it well below the measured thickness at $C / C_{0}=0.8$; see below for demonstration.

\section{Results and Discussion}

\subsection{Oxidation Study: TPO}

The results of TPO experiments on GPFs for each of the four fuel blends are shown in Fig. 5. The TPO indicates that the PM oxidative reactivities for the four fuel blends were impacted by both type and quantity of the alcohol blended. It was previously reported [16] that the chemical composition,
Fig. 3 Tomographic slices across the axial center plane for the fully loaded (left) and fully regenerated (right) GPFs. The bright arcs on the filter outer surface are hydrogenous adhesives in tapeholding aluminum foil wrapping in place
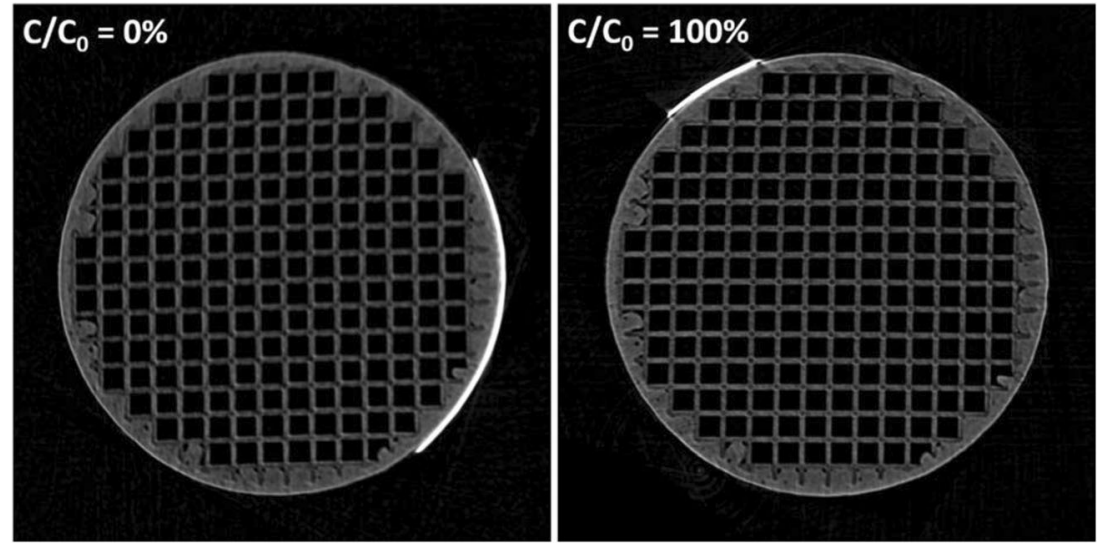


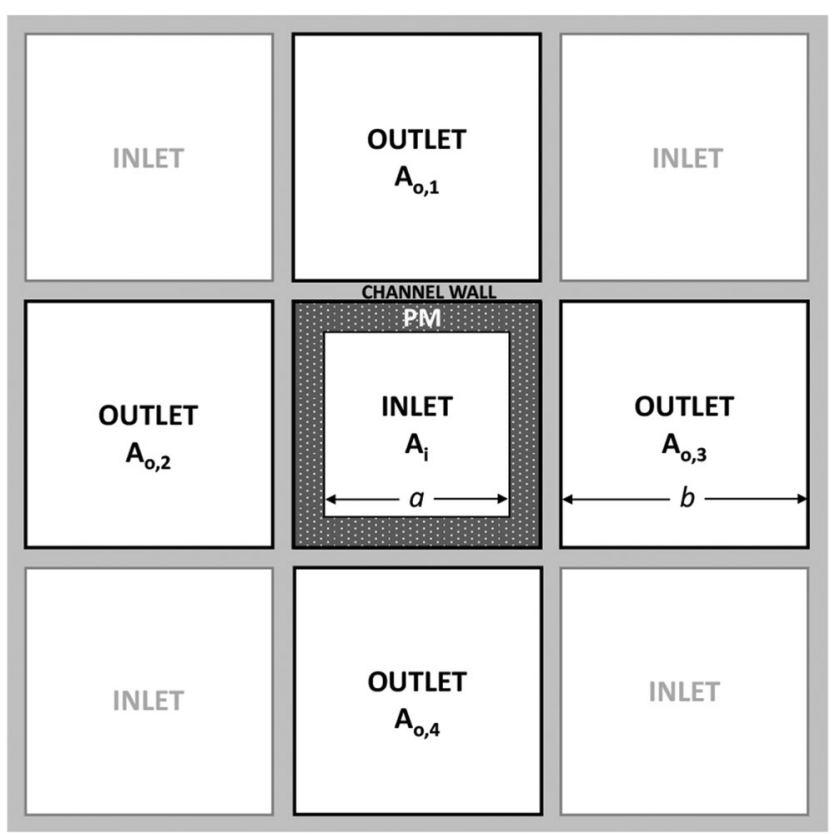

Fig. 4 Schematic of open-channel areas measured with image analysis and geometric factors used in determining PM layer thickness

particle size, and quantity of PM generated were also impacted by the type of alcohol in the fuel blend used to operate the engine. The temperatures at which $50 \%\left(T_{50}\right)$ and $90 \%\left(T_{90}\right)$ of the PM were oxidized during the TPO experiments (Table 2) highlight the higher oxidation temperatures required for PM from isobutanol fuel blends and dramatically lower temperatures needed for an ethanol blend compared with neat gasoline (no alcohol, E0). The oxidative reactivity of PM based on these TPO experiments follows E30 $>$ E0 $>$ iBu24 $\approx \mathrm{iBu} 48$. The TPO profile for E30 is shifted to lower temperatures and has a broader, more symmetric profile than the other fuels. Less active low-temperature oxidation $(\leq$ $550{ }^{\circ} \mathrm{C}$ ) is seen for $\mathrm{E} 0, \mathrm{iBu} 24$, and $\mathrm{iB} 48$ than for the E30

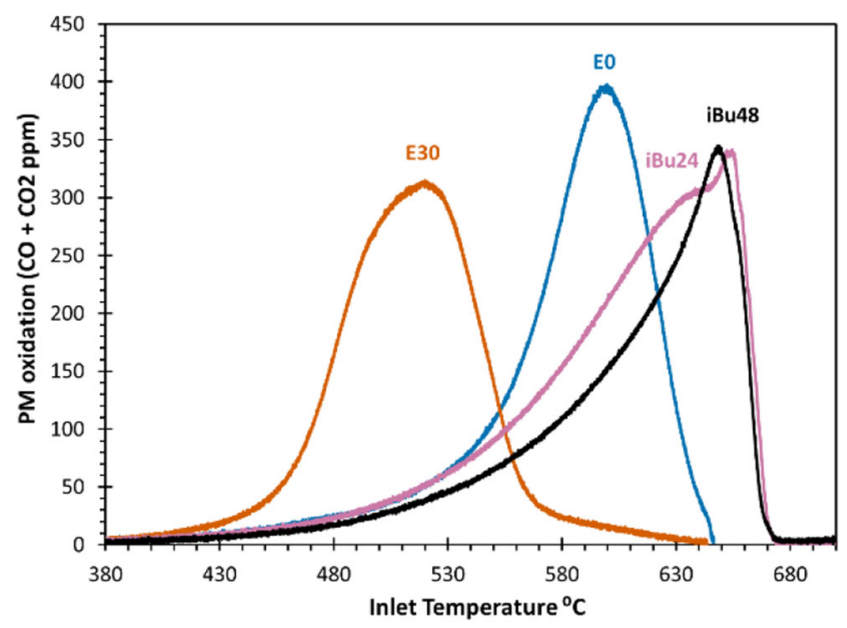

Fig. 5 PM oxidative reactivity from TPO experiments of 4 different gasoline blended fuels: E0 (100\% gasoline): E30 (30\% ethanol blend): $\mathrm{iBu} 24$ (24\% isobutanol blend): $\mathrm{iBu} 48$ (48\% isobutanol blend)
PM, resulting in asymmetric oxidation profiles and highlighting the difference ethanol can make on the PM properties. The greater low-temperature reactivity of E30 PM may be related to previously reported oxygen incorporation into the backbone of E30 PM, analytically detected as methyl propenoate [16]. The addition of ethanol to the gasoline dropped the $T_{90}$ of the resulting PM by $65^{\circ} \mathrm{C}$. In contrast, the addition of isobutanol increased the $T_{90}$ of the corresponding PM more than $100{ }^{\circ} \mathrm{C}$ compared with the neat gasoline PM, for both concentrations of isobutanol fuel blends studied.

\subsection{Oxidation Study: Kinetics}

\subsubsection{Activation Energy by Pulsed Oxidation}

As described in the Section 2, Table 1, isothermal, pulsedoxidation studies were used to obtain isothermal oxidation rates in a kinetically controlled range, like those shown in Fig. 6. These rates were used in the Arrhenius equation to calculate activation energies for the PM collected with the E0 and E30 fuel blends. The activation energies, at each of the five different levels of PM burnout, for all GPF samples studied are plotted in Fig. 7. Figure 8 simplifies the results of Fig. 7 showing activation energy averages with $\mathrm{min} / \mathrm{max}$ error bars for the five nominal burnout levels of the GPF PM studied $\left(C / C_{0}=0,0.2,0.4,0.6\right.$, and 0.8). For comparison, Fig. 8 includes values reported by Pihl et al. [39] for a similar DPF PM oxidation study.

The activation energies of the PM for both fuel blends in this study (E0 and E30) at each burnout level, shown in Fig. 7 and Fig. 8, suggest that as PM is removed by oxidation, the chemical stability of the remaining PM increases, resulting in higher activation energies. The activation energies reported [39] for diesel particulate, still loaded on a particulate filter, indicate no change in the chemical stability $(127 \mathrm{~kJ} / \mathrm{mol})$ of the PM using comparable burnout levels ( $\sim 0.2$ to $\left.0.7 \mathrm{C} / \mathrm{C}_{0}\right)$. The PM from both E0 and E30 GDI fuels, reported here, initially has lower activation energies (ca. 60-80 kJ/mol) than commonly reported for diesel PM, but by $60 \%$ burnout, these GDI PM activation energy values exceeded typical diesel activation energies. The PM generated from E30 remains chemically less stable than that from the E0 under oxidative conditions up to $70-75 \%$ burnout, at which point the activation
Table 2 Results from PM TPO study: temperatures at which $50 \%$ of $\mathrm{PM}$ is oxidized $\left(T_{50}\right)$ and $90 \%\left(T_{90}\right)$

\begin{tabular}{lll}
\hline & $T_{50}\left({ }^{\circ} \mathrm{C}\right)$ & $T_{90}\left({ }^{\circ} \mathrm{C}\right)$ \\
\hline E0 & 581 & 614 \\
E30 & 513 & 549 \\
iBu24 & 616 & 654 \\
iBu48 & 623 & 654 \\
\hline
\end{tabular}




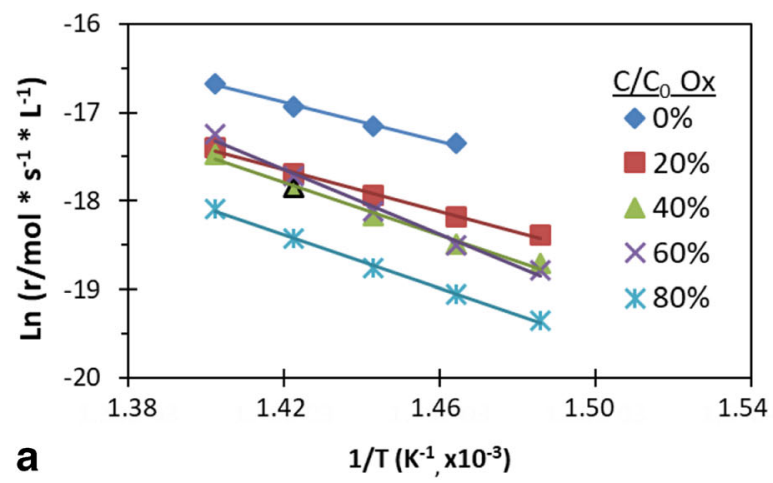

* Inclusion of the $\mathrm{Ln} \mathrm{r}$ for $\mathrm{C} / \mathrm{C}_{0}$ Ox of $0 \%$ at $400 \% \mathrm{C}$ drops the linear regression fit below $\mathrm{R}^{2}=0.96$

Fig. 6 a Arrhenius plots for oxidation of PM on an E0 GPF with linear best fits used for activation energy calculations. Oxidation is plotted in terms of rate, $r(\mathrm{~mol} / \mathrm{s})$, of PM oxidation divided by the total volume $(\mathrm{L})$ of the GPF sample as a function of temperature, $T(\mathrm{~K})$. b The five, $30 \mathrm{~s}$ duration, $\mathrm{O}_{2}$ pulses with a 150 -s delay between pulses for a E0 GPF

energy of both types of PM was seen to converge at about 170 kJ/mol; see Fig. 8.

The oxidative chemical stability of the PM from 0 to $60 \%$ burnout increased linearly for both E0 and E30. As can be
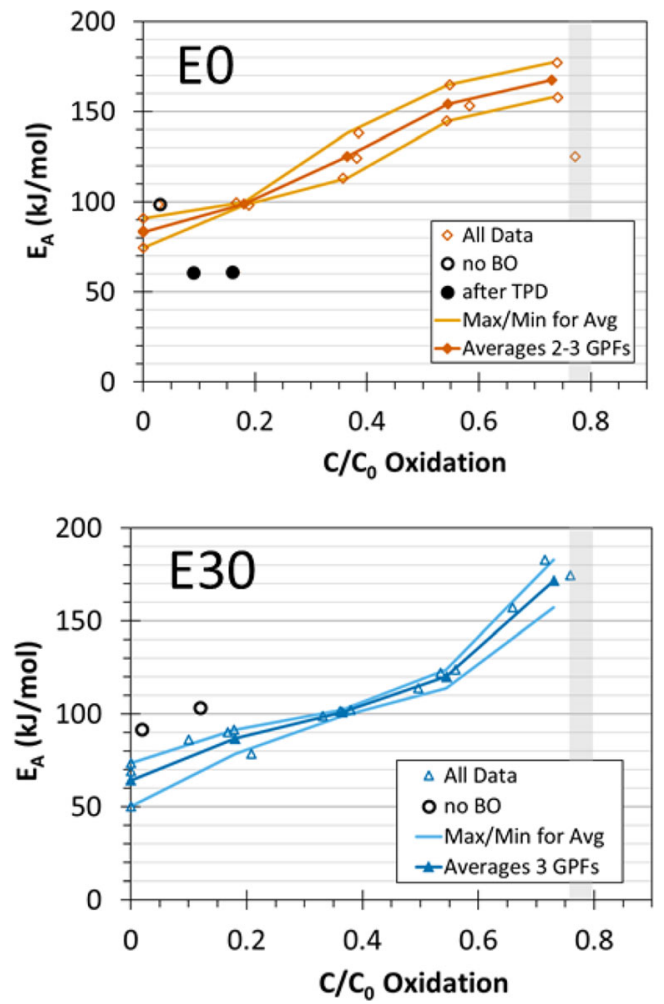

Fig. 7 Activation energy $\left(E_{\mathrm{A}}\right)$ plot of all data as a function of fraction of moles of carbon oxidized from loaded mini-GPF cores $\left(C / C_{0}\right.$ oxidation): $E_{\mathrm{A}}$ calculated from pulsed-oxidation experiments performed after a burnout oxidation treatment $(\Delta)$; directly after another pulsed-oxidation experiment $(\circ)$; and after a TPD oxidation $(\bullet)$. The average $E_{\mathrm{A}}$ for the 5 targeted $C / C_{0}$ oxidation levels ( $\boldsymbol{\Lambda}$, dark line) and the corresponding min and max values from the averages (no markers, lighter lines) are also shown

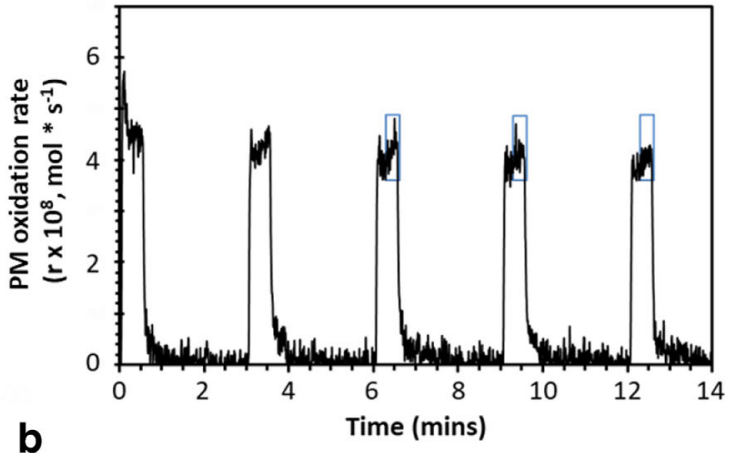

sample at $430{ }^{\circ} \mathrm{C}$ with a $C / C_{0}=0.4$. The blue boxes in $\mathbf{b}$ indicate the last $15 \mathrm{~s}$ of the last three pulses used to calculate an average oxidation rate which was averaged with data from two other E0 GPF samples to calculate the $\boldsymbol{\Delta}$ data point in a outlined in black

seen in the average activation energy plot, Fig. 8 , the chemical stability for E30 increased more rapidly with successive PM burnouts than E0, making the PM harder to oxidize. While the rate of increase in the activation energy as a function of burnout continued for E0 up to $74 \%$ burnout, a sharp increase was observed for E30 from 60 to $73 \%$ burnout. At the final burnout level studied, E0 and E30 both converged at an activation energy near $170 \mathrm{~kJ} / \mathrm{mol}$. Prior to the PM activation energies of E0 and E30 converging, E30 PM had a lower overall chemical stability than the E0 PM, which agrees with the oxidative reactivity seen in the TPO experiments discussed earlier where more of the E30 PM burned out at a lower temperature than the E0 PM.

The activation energy measurement for one of the E0 PM samples at the nominally 0.8 burnout point dropped significantly compared with the other two E0 GPF samples (see

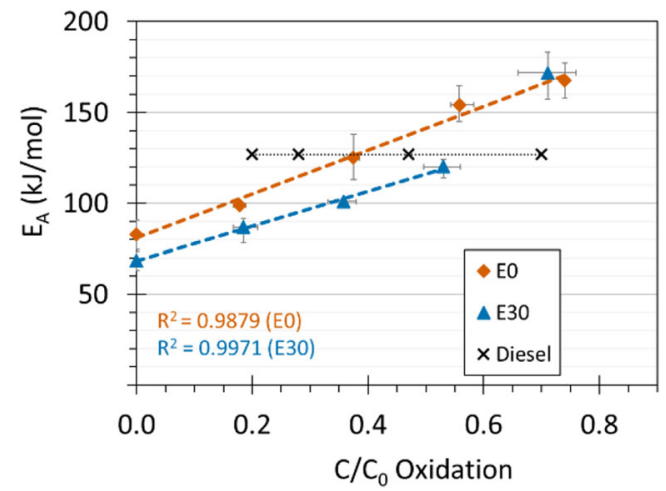

Fig. 8 Average activation energy $\left(E_{\mathrm{A}}\right)$ as a function of carbon oxidized on the loaded particulate filter $\left(C / C_{0}\right)$ for E30 PM (orange triangles), E0 PM (blue diamonds), and reported diesel PM (black x). Error bars for both activation energy (vertical) and $C / C_{0}$ (horizontal) represent min and max values for each average used. All averages for $\mathrm{E} 0$ and $\mathrm{E} 30$ were from $3 \mathrm{GPF}$ cores, except the $\mathrm{E} 0 \mathrm{C} / C_{0}$ oxidation values at $18 \%$ and $74 \%$ which are of only 2 GPF cores. Trendline for E30 does not include nominal 0.8 $C / C_{0}$ point 
orange diamonds in Fig. 7). However, since this drastically different data point could not be repeated within the scope of the project, it was not included in the average value at this nominal burnout level.

All of the trends discussed thus far were observed when the pulsed oxidation-temperature sweep, steps 2-6 in Table 1, was run following a step 1 burnout oxidation. Two different types of deviation from the steps 1-12 sequence were also performed in the course of the study and resulted in widely different impacts on the measured PM activation energy, as can be seen with the open and filled circle data points in Fig. 7. The open circles in Fig. 7 occurred when steps 2-6 were immediately repeated, resulting in the activation energy calculated from the second set of pulsed oxidations being greater than expected from the trends for both E0 and E30 samples. The second type of deviation resulted in lower than expected activation energies, filled circles in Fig. 7, and occurred when the E0 activation energies were calculated from steps 2-6 run after a TPD oxidation, steps 11-12, without running step 1 in between. This treatment was performed twice on the same E0 PM sample core, and in both cases, the calculated activation energy was the same, $61 \mathrm{~kJ} / \mathrm{mol}$, even though the $C / C_{0}$ had changed and was the lowest calculated for E0 under any set of conditions but fell close to the average seen for the fully loaded E30 PM $\left(C / C_{0}=0\right)$.

Once it was observed that the sequence of the oxidation experiments influenced the measured activation energies, a consistent sequence of experiments was performed at each level of PM oxidation studied, such that pulsed oxidation (steps 2-6) was only performed immediately following a burnout oxidation (step 1) experiment. Thus, more studies would be required to determine if these impacts on activation energy would continue at higher burnout levels. The changes in activation energy observed as a result of the PM's previous oxidizing environment suggest that multiple types of PM exist which have different barriers to oxidation.

Assuming the experiments were operating under the targeted isothermal, kinetically controlled conditions, the activation energy changes seen at successive $C / C_{0}$ burnout levels may also indicate the presence of different types of PM, with different activation energies, in varying fractional combinations. Since the PM in each of the GPFs studied was generated at the same constant engine conditions, all of the PM generated from a given fuel would be expected to have a consistent chemical makeup. This chemical makeup would correspond to the fractional distribution of the different types of PM and associated hydrocarbons at $C / C_{0}=0$. Earlier work [16] from our lab reported that some of the chemical properties, characterized from other PM samples from this study, varied between the E0 and E30 PM. PM samples characterized in the earlier report were collected on supported Teflon membrane filters during the same engine campaign as the GPFs discussed in this manuscript. Briefly, the chemical speciation of the PM samples was performed using a gas chromatography-mass spectrometer (GC-MS) to measure the hydrocarbon compounds produced during a thermal desorption step at $325{ }^{\circ} \mathrm{C}$ under helium and a pyrolysis step at $500^{\circ} \mathrm{C}$, collectively called a thermal desorption pyrolysis (TDP). All reported observations were made after normalizing for mass of PM analyzed and fraction of gasoline in the fuel blend. Note that the thermal desorption was done below the temperatures used in this GPF kinetic oxidation study while the pyrolysis step was at a higher temperature than the GPF samples were exposed to during steps 2-6, from which the activation energies were derived. The reported speciation of hydrocarbons released in the thermal desorption step indicated that the E0 PM had a greater fraction of polyaromatic hydrocarbons (PAHs) compared with E30. The pyrolysis step at $500{ }^{\circ} \mathrm{C}$ served to break down the particulate into subcomponents; those which elute earlier in the GC-MS measurement are typically considered to reveal PM backbone structural differences. Unique to E30 PM was the presence of methyl propenoate, an oxygenate, not seen in the E0 PM, suggesting that fuel oxygen had been incorporated into the backbone of the E30 PM. During the $500{ }^{\circ} \mathrm{C}$ pyrolysis step, E30 PM was shown to contain a higher concentration of multi-ring PAHs than E0 when normalized to the fraction of gasoline in the fuel blend. Considering this previous work from our lab, the types of PM could be categorized into (1) lower boiling point hydrocarbons, (2) higher boiling point hydrocarbons, (3) carbonaceous PM, often referred to as soot, and (4) oxygenated PM. Based on the different chemical properties of these different types of PM material, the changes in their fractional distribution could be expected to alter the stability and reactivity of the PM matrix as seen in the activation energies reported here.

The isothermal DPF study reported by Pihl et al. [39], which observed a constant activation energy of $127 \mathrm{~kJ} / \mathrm{mol}$ for diesel PM on a DPF at all levels of PM burnout, followed an oxidation sequence similar to steps 1-12 that were repeated in order at each increasing burnout level. However, the Pihl et al. study used a burnout oxidation temperature of $600{ }^{\circ} \mathrm{C}$ (step 1) immediately prior to its pulsed oxidation-temperature sweep (steps 2-6) while the GPF study, reported herein, used $440{ }^{\circ} \mathrm{C}$ in step 1 . When the activation energy was calculated for GPF PM samples immediately after a TPD oxidation (i.e., followed step order 11-12, 2-12, 2-6) which took the temperature to $650{ }^{\circ} \mathrm{C}$ for two consecutive $C / C_{0}$ PM oxidation levels (filled circles, Fig. 7), the activation energy did not change, indicating that steps 11-12 exposed similar PM material. Interestingly, when the test sequence returned to the typical steps $1-12,1-12$, etc. order, the increasing activation energies were again observed.

\subsubsection{Oxygen Dependence by Pulsed Oxidation}

Using the reaction rates obtained from the pulsed oxidation$\mathrm{O}_{2}$ sweep experiments (steps 6-10 in Table 1), the rate of PM 
oxidation was found to be 0.8 order in oxygen. This approximately first-order dependence on oxygen was consistent for oxidation at all $C / C_{0}$ on both $\mathrm{E} 0$ and $\mathrm{E} 30 \mathrm{PM}$.

\subsubsection{PM Active Surface Area by TPD Oxidation}

If the morphology of the PM layer impacted the activation energy measurement, the PM active surface area (SA) may contribute more to the reactivity than the fraction or quantity of PM on the GPFs. To assess this, the active SAs were calculated from production of $\mathrm{CO}$ and $\mathrm{CO}_{2}$ during the TPD oxidation experiments, steps 11-12, shown in Fig. 9. These active surface area measurements were taken following steps 2-10 at each $C / C_{0}$ burnout level. The molar specific active surface area $\left(S_{\mathrm{m}}, \mathrm{m}^{2} / \mathrm{mol}_{\mathrm{PM}}\right)$ at each $C / C_{0}$ was normalized to the GPF's initially measured molar SA $\left(S_{\mathrm{m}, 0}\right), C / C_{0}=0$, to allow better correlation across the multiple GPF samples studied for each fuel. The normalized data $\left(S_{\mathrm{m}} / S_{\mathrm{m}, 0}\right)$ are also plotted as a function of PM burnout, $C / C_{0}$, in Fig. 9. The trend lines seen in Fig. 9 suggest that a linear relationship exists between the burnout level and the normalized data for both E0 and E30 PM. A slight deviation in the linear relationship
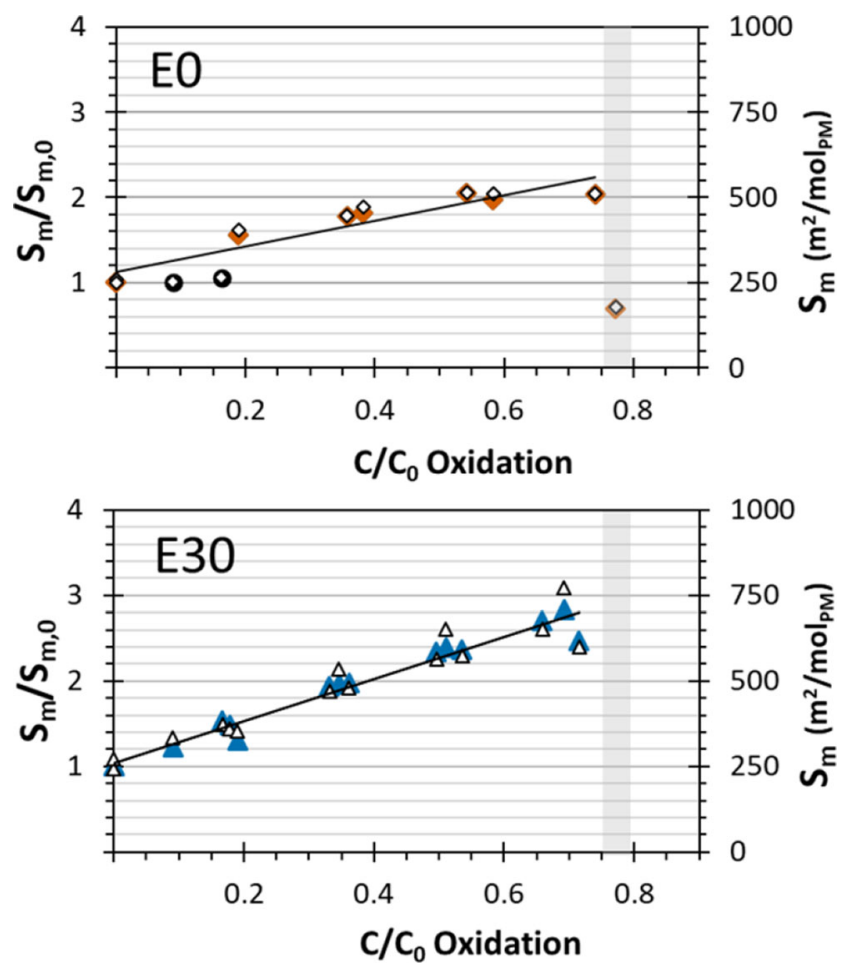

Fig. 9 Normalized molar active surface area $\left(S_{\mathrm{m}} / S_{\mathrm{m}, 0}\right)$ as a function of the amount of carbon oxidized from the GPF $\left(C / C_{0}\right)$ is plotted in the primary $y$ axis (filled symbols). The smaller, black, open symbols corresponding active surface areas without normalization $\left(S_{\mathrm{m}}\right)$ and are plotted against the secondary $y$ axis. Data is from 2 GPFs loaded with E0 PM (top) and from 3 GPFs loaded with E30 PM (bottom). The E0 linear best fits do not include the filled circles which represent molar surface area values obtained from TPD oxidation when there was a deviation from the order described in Table 1 or the diamond located in the gray band for the E0 PM occurs when the TPD oxidation followed steps 2-10 run without a burnout oxidation (i.e., followed step order 11-12, 2-12). The $S_{\mathrm{m}} / S_{\mathrm{m}, 0}$ observed in these cases (filled circles, Fig. 9) deviated from the trend found when calculated from runs that followed the repeated step 1-12 order. The molar active surface area also dropped lower than the trendline at the $C / C_{0}=0.8$ burnout level for the E0 (gray band, Fig. 9). In both cases, the PM also had an activation energy which dropped below the trend, as discussed above (Fig. 7 and Fig. 8).

The greater active surface area per mole of PM remaining on the E30 GPF vs. E0 indicates that either more of the PM on E30 is physically accessible to the oxygen, and/or that the PM from the different fuels is physically or chemically different. The lower-temperature reactivity, activation energies, and compositional differences discussed earlier all suggest that the higher active surface area of E30 can be attributed to different types of PM and/or the fractional distribution of these types compared with E0.

\subsection{Neutron Imaging of PM Layer During Oxidation}

A morphological study of the PM layer thickness was performed using neutron imaging of PM-loaded mini-GPF cores as successive fractions of the PM were removed by burnout oxidation $\left(C / C_{0}=0,0.2,0.4,0.6,0.8\right.$, and 1.0$)$ according to step 1 of Table 1 . The two cores imaged were loaded from either E0 or E30 engine operation at the same time as those used in the TPO and kinetic studies reported above. The E0 and E30 cores were first imaged in the neutron beam fully loaded to $C / C_{0}=0$. Between neutron-imaging experiments, $20 \%$ of the PM loading was removed by burnout, and then the cores were imaged using the neutron beam. The burnout and neutron imaging were repeated four more times for each core with the final oxidation $\left(C / C_{0}=1.0\right)$ removing all remaining PM such that the final images captured the channel structure of the empty, unloaded GPF cores.

While the PM deposit profile, measured by neutron imaging, down the length of the channels was similar for both E0 and E30 PM fully loaded, changes in the PM thickness profile from the different fuels differed at successive PM burnout levels. The results in Fig. 10 are condensed in Fig. 11, showing the fractional change in average PM layer thickness at 7 , 20,40 , and $60 \mathrm{~mm}$ down the length of the GPF channels with each sequential burnout. Note that $0 \mathrm{~mm}$ from the front of the GPF is in the channel plug region of the filter and hinders thickness analysis; $7 \mathrm{~mm}$ was selected as representative of the front end of the filter as it is past the channel plugs.

The un-regenerated E0 PM layer $\left(C / C_{0}=0\right.$, Fig. 10 and Fig. 11) had a thicker deposit at the back of the GPF. The PM layer then burned off proportionally down the middle length $(20-60 \mathrm{~mm})$ of the channels for $C / C_{0}=0.2$ and 0.4 , but the thickness was only reduced by $\sim 10 \%$ for each 


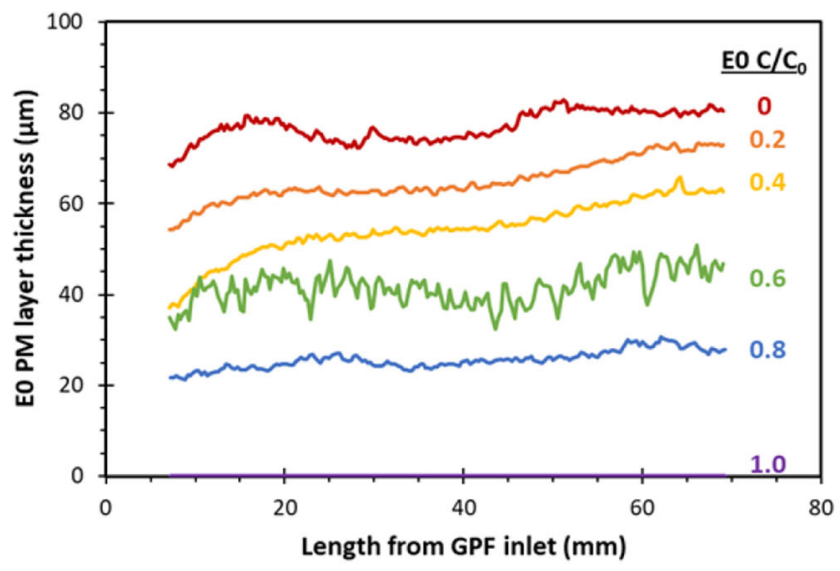

Fig. 10 Thickness profiles, derived from neutron imaging, of the PM layers along the length of the GPF channel. The $x$ axis indicates the length $(\mathrm{mm})$ from the inlet of the GPF. Plots show the changes in the

burnout, suggesting that at least a fraction of the PM removed during burnout was located throughout the depth of the layer, potentially increasing its porosity. The neutron-imaging approach does not account for any PM located within the walls
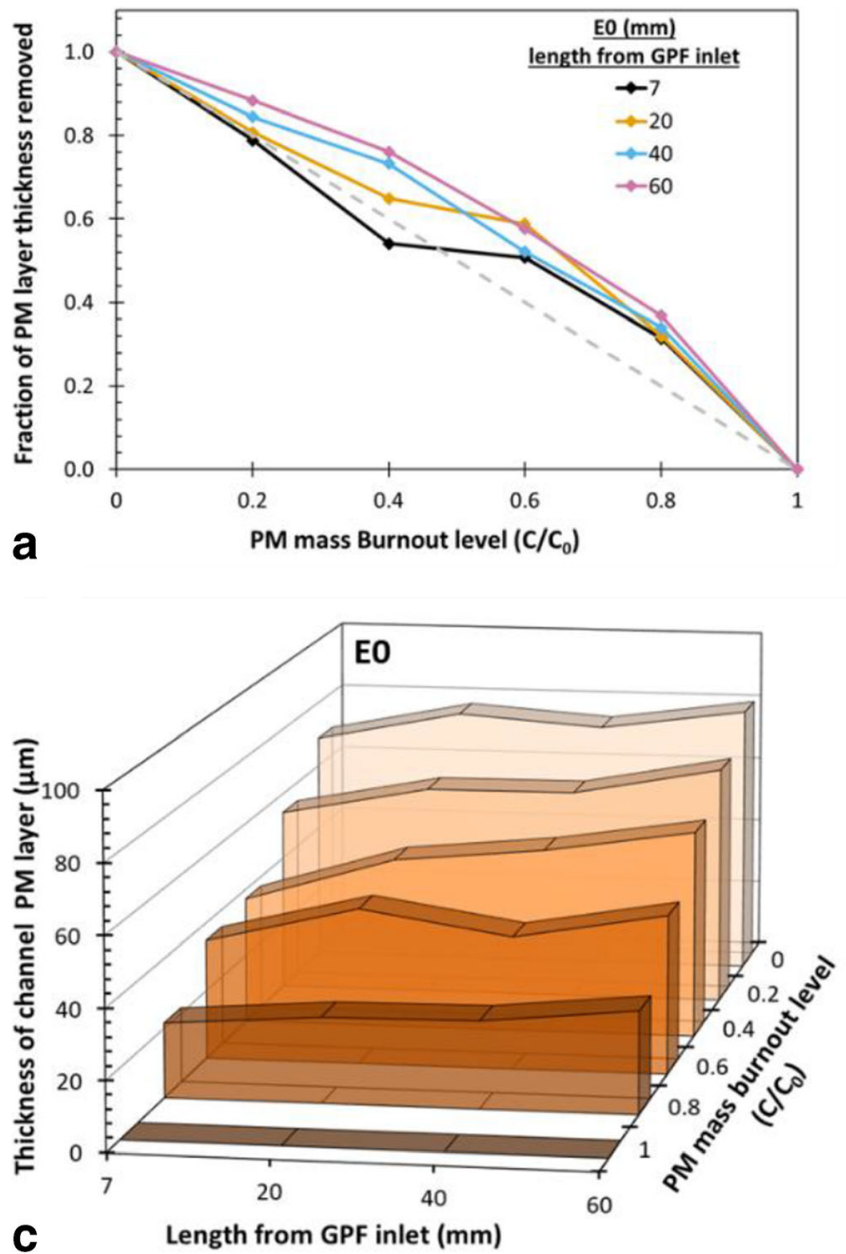

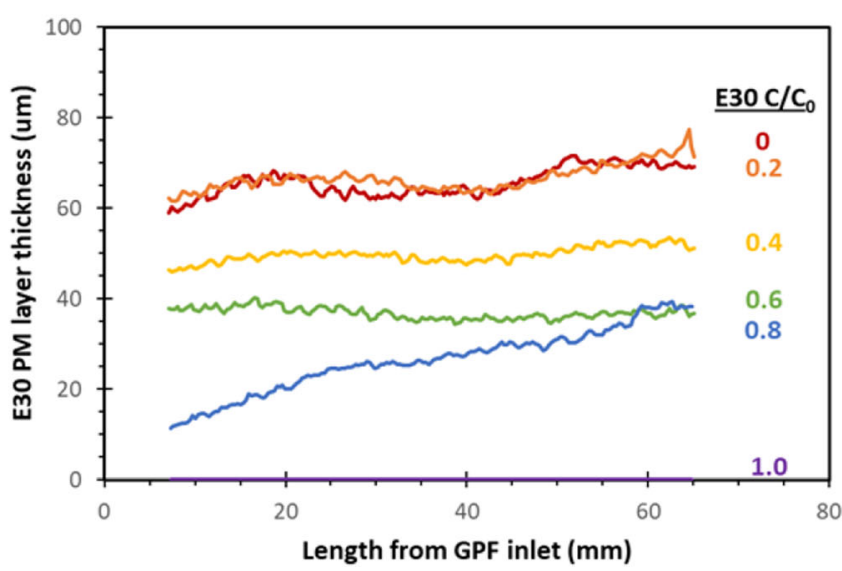

average E0 (left) and E30 (right) PM thickness profiles from the same GPF channels after successive fractions of the PM mass are removed by burnout oxidation

of the GPF that could also contribute to the smaller reduction in thickness. The thickness of the PM layer near the inlet of the GPF, which began thinner, dropped proportionally to the $20 \%$ mass reduction between each burnout. After removing another
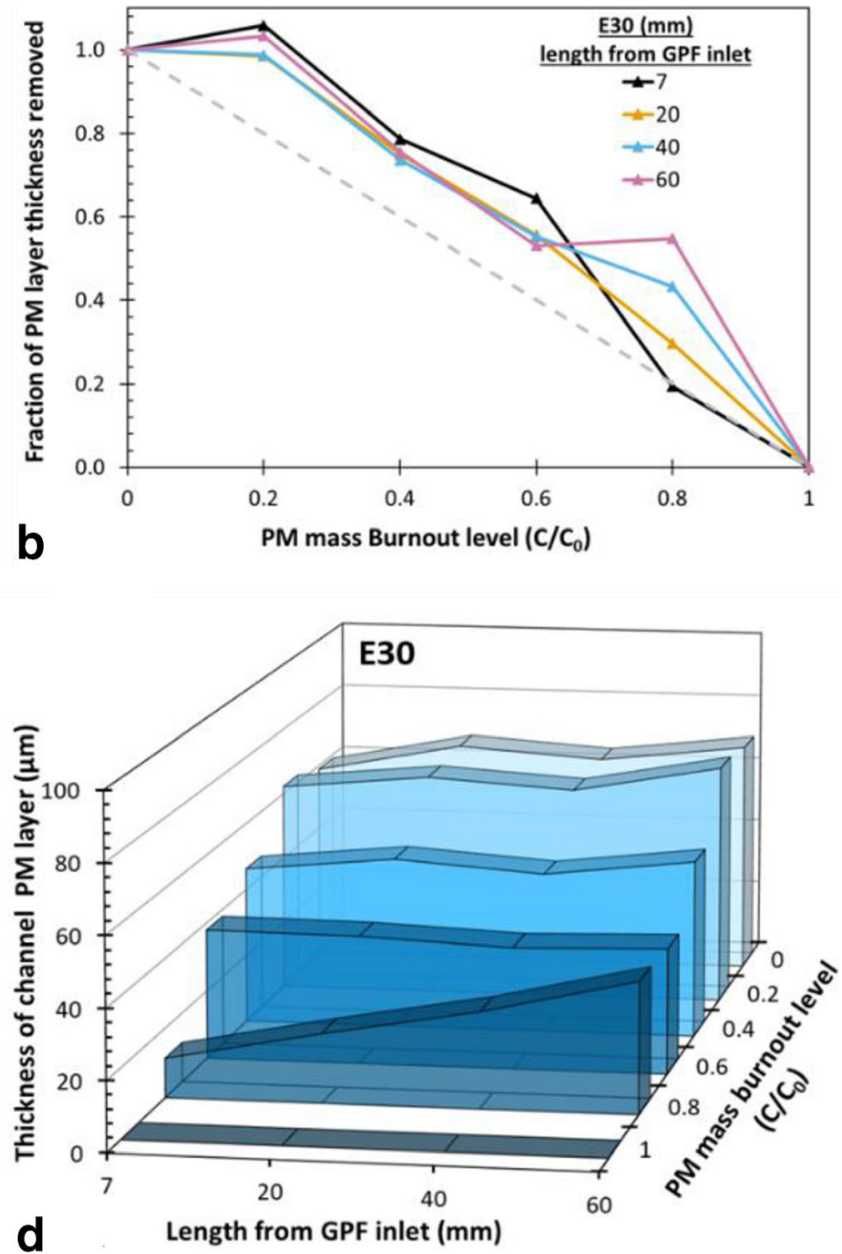

Fig. 11 Simplified PM thickness profiles from the neutron-imaging results presented in Fig. 10 as increasing fractions of the PM were removed by burnout oxidation. Plots a and $\mathbf{c}$ display the same E0 results while plots $\mathbf{b}$ and $\mathbf{d}$ display the same E30 result in 2D and 3D plots, respectively 
$20 \%$ of the E0 PM mass deposit $\left(C / C_{0}=0.6\right)$, no thickness change was observed at the inlet of the GPF, while the rest of the layer down the length of the channels showed a $30 \%$ drop in thickness after the burnout. The result of these different thickness changes along the length of the PM layer resulted in consistent PM thickness along the entire channel length after the $60 \%$ burnout. During the burnout to $C / C_{0}=0.8$, the front of the layer was more readily removed while a roughly $20 \%$ reduction in thickness was seen down the channels. With only $20 \%$ of the E0 PM left in the GPF, the thickness of the PM layer still had nearly $30 \%$ of its initial, fully loaded thickness, suggesting the PM removed during the prior burnout came from throughout the depth of the layer or within the wall.

The thickness of the E30 PM layer behaved differently (Fig. 10 and Fig. 11) during the same set of successive burnout steps as the E0-loaded GPF. After the first $20 \%$ of the PM mass was removed, little to no change in the layer thickness was observed down the length of the channels. This suggests that either a significant increase in porosity within the PM deposit had to have occurred without the layer collapsing, or the majority of the PM removed was located in the filter walls. At $C / C_{0}=0.4$, a uniform layer thickness was observed down the length of the channel, showing a $25 \%$ drop in thickness compared with the previous burnout. The layer thickness change from 0.4 to 0.6 burnout showed another $\sim 25 \%$ drop in thickness except at the front of the channel where the thickness change was less than $20 \%$. During the 0.8 burnout, most of the remaining PM located in the front of the channels was removed, but the fraction of PM removed down the rest of the channel gradually diminished, with no reduction in the thickness at $60 \mathrm{~mm}$ down the channels. These results are in contrast to a neutron-imaging study of PM layers in a diesel-loaded DPF for which Toops et al. reported [33] the PM layer thickness along the channels collapsed by a third after only $20 \%$ burnout, and the PM layers at the back of the channels, near the filter plug, burned out first. A study by Sappok et al. [43] on DPF regeneration had previously reported that the soot/PM cake reached complete regeneration only near the inlet. Toops et al. [33] suggested the presence of ash at the back of the DPF channels in Sappok's study likely blocked oxygen access near the rear.

\section{Conclusions}

The results of this study suggest that GDI PM trapped in a GPF is not uniform, and the oxidative reactivity of GDI PM depends on fuel composition and exposure history, and evolves in a complex manner over the course of filter regeneration.

- The oxidation reactivity of PM generated by a GDI engine varies significantly with the composition of the fuel. E30 generates PM with much higher oxidation reactivity than E0 gasoline, while iBu24 and iBu48 generate PM with much lower reactivities.

- The oxidation kinetics of GDI PM depend on its exposure history. PM that has been exposed to $650{ }^{\circ} \mathrm{C}$ under inert conditions is much less reactive than PM that has been recently exposed to $\mathrm{O}_{2}$ and $\mathrm{H}_{2} \mathrm{O}$ at moderate temperatures.

- The chemical reactivity and physical properties of GDI PM collected in a GPF continuously vary as the PM is oxidized. The activation energy for oxidation by $\mathrm{O}_{2}$ increases linearly as the PM is oxidized, indicating that overall reactivity of the PM is decreasing as the PM is consumed. The active surface area of the PM also increases linearly as the PM is oxidized, contrary to what might be expected based on the reactivity trends.

- The variations in chemical and physical properties with oxidation indicate that GDI PM behaves very differently from diesel PM.

- The thickness of the PM layer in the GPF channel does not decrease uniformly over the course of oxidation. The observed variations in PM layer thickness are consistent with multiple stages of GPF regeneration that could include preferential oxidation of PM embedded in the filter wall; increasing porosity of the PM layer; and subsequent collapse of the more porous layer. The evolution of the PM layer during GPF regeneration is different for different fuels.

While a GPF used in the aftertreatment system of a GDI vehicle may not be expected to accumulate as much of a PM layer [23] as was present in these studies, the intrinsic kinetics of GDI PM oxidation, and how they vary with fuel composition and with the progression of the regeneration process, should provide useful insights to designers of control strategies for engines equipped with GPFs. Furthermore, the decreasing reactivity of GDI PM as oxidation progresses could result in accumulation of very unreactive PM within GPFs over certain drive cycles. The findings from this study will help in the development of active regeneration strategies for such instances. Studies that compare the PM reactivities presented here to PM generated during the first seconds of a cold start and/or kinetics from the use of other oxidants would further develop the understanding of GDI PM emissions.

Acknowledgments The authors thank Lou Santodonato and Indu Dhiman for the technical assistance during neutron imaging of the GPF cores. Additionally, the authors thank Jim Szybist for access to the engine and training needed to operate it. 
Funding Information Primary funding for this work was provided by the US Department of Energy's Vehicle Technologies Office (VTO) with a portion of this funding coming from the Co-Optimization of Fuels and Engines Initiative. The authors greatly appreciate support from Kevin Stork at VTO. This research also used resources at the High Flux Isotope Reactor, a DOE Office of Science User Facility, and the National Transportation Research Center, a DOE Office of Energy Efficiency and Renewable Energy User Facility, both operated by the Oak Ridge National Laboratory.

\section{Compliance with Ethical Standards}

Competing Interests The authors declare that they have no competing interests.

Open Access This article is licensed under a Creative Commons Attribution 4.0 International License, which permits use, sharing, adaptation, distribution and reproduction in any medium or format, as long as you give appropriate credit to the original author(s) and the source, provide a link to the Creative Commons licence, and indicate if changes were made. The images or other third party material in this article are included in the article's Creative Commons licence, unless indicated otherwise in a credit line to the material. If material is not included in the article's Creative Commons licence and your intended use is not permitted by statutory regulation or exceeds the permitted use, you will need to obtain permission directly from the copyright holder. To view a copy of this licence, visit http://creativecommons.org/licenses/by/4.0/.

\section{References}

1. U.S. Environmental Protection Agency, "The 2018 EPA automotive trends report: greenhouse gas emissions, fuel economy, and technology since 1975, EPA-420-R-19-002," March 2019

2. B. Giechaskiel, A. Joshi, L. Ntziachristos and P. Dilara, "European regulatory framework and particulate matter emissions of gasoline light-duty vehicles: a review," Catalysts, vol. 9, no. 586, 2019. https://doi.org/10.3390/catal9070586

3. Saliba, G., Saleh, R., Zhao, Y., Presto, A.A., Lambe, A.T., Frodin, B., Sardar, S., Maldonado, H., Maddox, C., May, A.A., Drozd, G.T., Goldstein, A.H., Russell, L.M., Hagen, F., Robinson, A.L.: Comparison of gasoline direct-injection (GDI) and port fuel injection (PFI) vehicle emissions: emission certification standards, coldstart, secondary organic aerosol formation potential, and potential climate impacts. Environ. Sci. Technol. 51(11), 6542-6552 (2017). https://doi.org/10.1021/acs.est.6b06509

4. Chen, L., Liang, Z., Zhang, X., Shuai, S.: Characterizing particulate matter emissions from GDI and PFI vehicles under transient and cold start conditions. Fuel. 189, 131-140 (2017). https://doi.org/10. 1016/j.fuel.2016.10.055

5. Liang, B., Ge, Y., Tan, J., Han, X., Gao, L., Hao, L., Ye, W., Dai, P.: Comparison of PM emissions from a gasoline direct injected (GDI) vehicle and a port fuel injected (PFI) vehicle measured by electrical low pressure impactor (ELPI) with two fuels: gasoline and M15 methanol gasoline. J. Aerosol Sci. 57, 22-31 (2013). https:// doi.org/10.1016/j.jaerosci.2012.11.008

6. J. M. E. Storey, T. L. Barone, J. F. Thomas and S. P. Huff, "Exhaust particle characterization for lean and stoichiometric DI vehicles operating on ethanol-gasoline blends," SAE International, pp. 2012-01-0437, 2012. doi:https://doi.org/10.4271/2012-01-0437

7. J. E. Parks, J. M. E. Storey, V. Y. Prikhodko, M. M. DeBusk and S. A. Lewis, "Filter-based control of particulate matter from a lean gasoline direct injection engine," SAE Technical Paper, pp. 201601-0937, 2016. doi:https://doi.org/10.4271/2016-01-0937

8. Park, C., Lee, S., Yi, U.: Effects of engine operating conditions on particle emissions of lean-burn gasoline direct-injection engine. Energy. 115, 1148-1155 (2016)

9. Splitter, D., Pawlowski, A., Wagner, R.: A historical analysis of the co-evolution of gasoline octane number and spark-ignition engines. Front. Mech. Eng. 1, 16-1155 (2016). https://doi.org/10.1016/j. energy.2016.09.051

10. Storey, J.M., Barone, T., Norman, K., Lewis, S.A.: Ethanol blend effects on direct injection spark-ignition gasoline vehicle particulate matter emissions. SAE Int. J. Fuels Lubr. 3(2), 650-659 (2010. https://www.jstor.org/stable/26272966)

11. Mathis, U., Mohr, M., Forss, A.-M.: Comprehensive particle characterization of modern gasoline and diesel passenger cars at low ambient temperatures. Atmos. Environ. 39(1), 107-117 (2005). https://doi.org/10.1016/j.atmosenv.2004.09.029

12. Luo, Y., Zhu, L., Fang, J., Zhuang, Z., Guan, C., Xia, C., Xie, X., Zhang, Z.: Size distribution, chemical composition and oxidation reactivity of particulate matter from gasoline direct injection (GDI) engine fueled with ethanol-gasoline fuel. Appl. Therm. Eng. 89, 647-655 (2015). https://doi.org/10.1016/j.applthermaleng.2015. 06.060

13. J. Koczak, A. Boehman and M. Brusstar, "Particulate emissions in GDI vehicle transients: an examination of FTP, HWFET, and US06 measurements," SAE Technical Paper, Vols. 2016-01-0992, 2016. doi:https://doi.org/10.4271/2016-01-0992

14. J. M. Storey, M. Moses-DeBusk, M. A. Eibl, F. Li and S. Huff, "Characterization of GDI PM during vehicle start-stop operation," SAE Technical Paper, Vols. 2019-01-0500, 2019. doi:https://doi. org/10.4271/2019-01-0050

15. Maricq, M.M., Szente, J.J., Adams, J., Tennison, P., Rumpsa, T.: Influence of mileage accumulation on the particle mass and number emissions of two gasoline direct injection vehicles. Environ. Sci. Technol. 47(20), 11890-11896 (2013). https://doi.org/10.1021/ es402686z

16. Storey, J.M., Lewis, S.A., Szybist, J.P., Thomas, J.F., Barone, T.L., Eibl, M.A., Nafziger, E.J., Kaul, B.: Novel characterization of GDI engine exhaust for gasoline and mid-level gasoline-alcohol blends. SAE Int. J. Fuels Lubr. 7(2), 571-579 (2014)

17. Maricq, M.M., Szente, J.J., Jahr, K.: The impact of ethanol fuel blends on PM emissions from a light-duty GDI vehicle. Aerosol Sci. Technol. 46(5), 576-583 (2012). https://doi.org/10.1080/ 02786826.2011.648780

18. U.S. Environmental Protection Agency, "Light-duty automotive technology, carbon dioxide emissions, and fuel economy trends: 1975 through 2017, EPA-420-R-18-001.,” January 2018

19. "California's advanced clean cars midterm review. Appendix J: Vehicle PM Emission Control Technology Assessment," January 18, 2017

20. Delphi, "Delphi (2018) Worldwide Emissions Standardspassenger cars and light duty vehicles-2018/2019," Accessed November 2018

21. Moses-DeBusk, M., Curran, S.J., Lewis, S.S.A., Connatser, R.M., Storey, J.M.E.: Impacts of air-fuel stratification in ACI combustion on particulate matter and gaseous emissions. Emiss. Control Sci. Technol. 5(3), 225-237 (2019). https://doi.org/10.1007/s40825019-00122-5

22. Storey, J., Curran, S., Lewis, S., Barone, T., Dempsey, A., MosesDeBusk, M., Hanson, R., Prikhodko, V., Northrop, W.: Evolution and current understanding of physiochemical characterization of particulate matter from reactivity controlled compression ingnition combustion on a multicylinder light-duty engine. Int. J. Engine Res. 1(5-6), 1-15 (2017). https://doi.org/10.1177/1468087416661637 
23. Lambert, C.M., Chanko, T., Dobson, D., Liu, X., Pakko, J.: Gasoline particle filter development. Emiss. Control Sci. Technol. 3(1), 105-111 (2017). https://doi.org/10.1007/s40825-016-0055-x

24. Tandon, P., Heibel, A., Whitmore, J., Kekre, N., Chithapragada, K.: Measurement and prediction of filtration efficiency evolution of soot loaded diesel particulate filters. Chem. Eng. Sci. 65(16), 4751-4760 (2010). https://doi.org/10.1016/j.ces.2010.05.020

25. K. Tsuneyoshi, O. Takagi and K. Yamamoto, "Effects of washcoat on initial PM filtration efficiency and pressure drop in SiC DPF," SAE Technical Paper, Vols. 2011-01-0817, 2011. doi:https://doi. org/10.4271/2011-01-0817

26. Lambert, C.K., Bumbaroska, M., Dobson, D., Hangas, J., Pakko, J., Tennison, P.: Analysis of high mileage gasoline exhaust particle filters. SAE Int. J. Engines. 9(2), 1296-1304 (2016. https://www. jstor.org/stable/26284898)

27. X. Liu, J. Szente, C. Lambert and M. Maricq, "Using artificial ash to improve GPF performance at zero mileage," SAE Technical Paper, no. 2019-01-0974, 2019. doi:https://doi.org/10.4271/201901-0974

28. C. K. Lambert, T. Chanko, M. Jagner, J. Hangas, X. Liu and J. Pakko, "Analysis of ash in low mileage, rapid aged, and high mileage gasoline exhaust particulate filters," SAE Int. J. Engines, vol. 10, no. 4, 2017. doi:https://doi.org/10.4271/2017-01-0930

29. M. V. Nieuwstadt, A. Shah, E. Serban and D. Martin, "Regeneration strategies for gasoline particulate filters," $S A E$ Technical Paper, no. 019-01-0969, 2019. doi:https://doi.org/10. 4271/2019-01-0969

30. Bogarra, M., Herreros, J.M., Tsolakis, A., Rodríguez-Fernández, J., York, A.P., Millington, P.J.: Gasoline direct injection engine soot oxidation: fundamentals and determination of kinetic parameters. Combust. Flame. 190, 177-187 (2018). https://doi.org/10.1016/j. combustflame.2017.11.027

31. Wang, C., Xu, H., Herreros, J.M., Lattimore, T., Shuai, S.: Fuel effect on particulate matter composition and soot oxidation in a direct-injection spark ignition (DISI) engine. Energy Fuel. 28(3), 2003-2012 (2014). https://doi.org/10.1021/ef402234z

32. Chen, W., Xia, C., Zhu, L., Mao, K., Tao, J., Fang, J., Huang, Z.: An experimental study on combustion and particulate emissions characteristics on a dual-injection gasoline engine. Appl. Therm. Eng. 156, 722-729 (2019). https://doi.org/10.1016/j. applthermaleng.2019.04.069

33. Toops, T.J., Pihl, J.A., Finney, C.E., Gregor, J., Bilheux, H.: Progression of soot cake layer properties during the systematic regeneration of diesel particulate filters measured with neutron tomography. Emiss. Control Sci. Technol. 1(1), 24-31 (2015). https://doi.org/10.1007/s40825-014-0008-1
34. Toops, T.J., Bilheux, H.Z., Voisin, S., Gregor, J., Walker, L., Strzelec, A., Finney, C.E.A., Pihl, J.A.: Neutron tomography of particulate filters: a non-destructive investigation tool for applied and industrial research. Nucl. Instrum. Methods in Phys. Res. 729, 581-588 (2013). https://doi.org/10.1016/j.nima.2013.08.033

35. D. Gaspar, "Top ten blendstocks for turbocharged gasoline engines: bio-blendstocks with the potential to deliver the highest engine efficiency.," PNNL-28713, Pacific Northwest National Laboratory, 2019

36. Szybist, J.P., Youngquist, A.D., Barone, T.L., Storey, J.M., Moore, W.R., Foster, M., Confer, K.: Ethanol blends and engine operating strategy effects on light-duty spark-ignition engine particle emissions. Energy Fuel. 25(11), 4977-4985 (2011). https://doi.org/10. $1021 / \mathrm{ef} 201127 \mathrm{y}$

37. Jung, H.H., Shelby, M.H., Newman, C.E., Stein, R.A.: Effect of ethanol on part load thermal efficiency and $\mathrm{CO} 2$ emissions of SI engines. SAE Int. J. Engines. 6(1), 456-469 (2013). https://doi.org/ 10.4271/2013-01-1634

38. Short, D., Vu, D., Durbin, T.D., Karavalakis, G., Asa-Awuku, A.: Particle speciation of emissions from iso-butanol and ethanol blended gasoline in light-duty vehicles. J. Aerosol Sci. 84, 39-42 (2015). https://doi.org/10.1016/j.jaerosci.2015.02.010

39. Pihl, J.A., Lewis, J.A., Toops, T.J., Adelman, B.J., Derbowski, E.M.: Development of a surface area dependent rate expression for soot oxidation in diesel particulate filters. Top. Catal. 56(1-8), 499-503 (2013). https://doi.org/10.1007/s11244-013-0005-6

40. Santodonato, L., Bilheux, H., Bailey, B., Bilheux, J., Nguyen, P., Temsin, A., Selby, D., Walker, L.: The CG-1D neutron imaging beamline at the oak Ridge National Laboratory high flux isotope reactor. Phys. Procedia. 69, 104-108 (2015). https://doi.org/10. 1016/j.phpro.2015.07.015

41. Gregor, J., Benson, T.T.: Computational analysis and improvement of SIRT. IEEE Transactions in Medical Imaging. 27(7), 918-924 (2008). https://doi.org/10.1109/TMI.2008.923696

42. Gregor, J., Fessler, J.: A comparison of SIRT with SQS for regularized weighted least squares image reconstruction. IEEE Trans. Comput. Imaging. 1(1), 44-55 (2015). https://doi.org/10.1109/TCI. 2015.2442511

43. Sappok, A., Wang, Y., Wang, R.-Q., Kamp, C., Wong, V.: Theoretical and experimental analysis of ash accumulation and mobility in ceramic exhaust particulate filters and potential for improved ash management. SAE Int. J. Fuels Lubr. 7(2), 511-524 (2014) https://www.jstor.org/stable/26273043

Publisher's Note Springer Nature remains neutral with regard to jurisdictional claims in published maps and institutional affiliations. 